\title{
Predição da Composição Química de Bermudas (Cynodon spp.) pela Espectroscopia de Reflectância no Infravermelho Proximal ${ }^{1}$
}

\author{
Roberto Serena Fontaneli², Simone Meredith Scheffer-Basso ${ }^{3}$, João Walter Dürr ${ }^{4}$, \\ Jaques Valter Appelt ${ }^{5}$, Fernanda Bortolini ${ }^{6}$, Fabrício Adriano Haubert ${ }^{7}$
}

\begin{abstract}
RESUMO - Diversos cultivares de Cynodon dactylon têm sido cultivados no Rio Grande do Sul para alimentação do rebanho leiteiro, na forma de pastejo ou feno. A rápida determinação do valor nutritivo dessas forrageiras pode ser útil para seu manejo e para o planejamento da dieta dos animais. Este trabalho teve como objetivo desenvolver curvas de calibração para análise do valor nutritivo de quatro cultivares de Cynodon (Tifton 68, Tifton 85, Florakirk, Coastcross), utilizando o método de reflectância no infravermelho proximal (NIRS). Foram utilizadas 129 amostras de forragem verde, coletadas e analisadas entre 1998 e 2001. Os coeficientes de determinação para proteína bruta, fibra insolúvel em detergente neutro, fibra insolúvel em detergente ácido, matéria seca, cálcio, fósforo, potássio e magnésio foram, respectivamente: 0,$98 ; 0,97 ; 0,99 ; 1 ; 0,92 ; 0,97 ; 0,99$ e $0,72 \%$. Os erros-padrão de calibração foram de 0,$38 ; 0,60 ; 0,35 ; 0,14 ; 0,02 ; 0,01 ;$ 0,05 e 0,01\%, respectivamente. As equações obtidas foram consideradas de excelente resolução para todos os parâmetros estimados, o que indica a acurácia do método para a espécie avaliada.
\end{abstract}

Palavras-chave: análise de forrageiras, Coastcross, Florakirk, NIRS, Tifton

\section{Prediction of Chemical Composition of Cynodon spp. by Near Infrared Reflectance Spectroscopy}

\begin{abstract}
Many Cynodon dactylon cultivars have been cultivated in Rio Grande do Sul state to be used as pasture or hay to feed dairy cattle. Quick determination of the nutritional value of these forages would be valuable for management and diet planning. This work had the objective to develop calibration curves for analysis of the nutritional value of four Cynodon cultivars (Tifton 68, Tifton 85, Florakirk, Coastcross), using near infrared reflectance spectroscopy (NIRS). A total of 129 fresh samples of green pasture were collected and analyzed from 1998 to 2001. The determination coefficients for crude protein, neutral detergent fiber, acid detergent fiber, dry matter, calcium, phosphorus, potash and magnesium were, respectively, .98, .97, .99, 1, .92, .97, .99 and .72\%. The calibration standard error for the same parameters were $.38, .60, .35, .14, .02, .01, .05$ and $.01 \%$, respectively. Obtained equations were considered of excellent resolution for all estimated parameters, indicating the accuracy of the method for the species studied.
\end{abstract}

Key Words: Coastcross, forage analyzes, Florakirk, NIRS, Tifton

\section{Introdução}

As gramíneas tropicais têm sua composição química e qualidade rapidamente modificadas ao longo de seu desenvolvimento, em função de sua rápida taxa de crescimento. O monitoramento dessas alterações é fator determinante na produção animal, uma vez que a redução do valor nutritivo compromete o consumo e a utilização da forragem disponível.

Nas regiões do Planalto Médio e Missões, no Rio Grande do Sul, o cultivo das bermudas (Cynodon spp.) tem se intensificado nos últimos anos, em virtude do aumento das áreas destinadas à produção de leite. Entre os híbridos, destacam-se o Tifton 68 e o Tifton 85 , embora a cv. Tifton 85 seja apontada como o melhor híbrido até o momento, sendo de porte alto e hábito estolonífero-rizomatoso (Rocha et al., 2001), ao passo que a cv. Tifton 68 é estolonífera.

Jobim et al. (2001), ao testarem fenos de Tifton 85 e alfafa (Medicago sativa L.) na alimentação de vacas leiteiras, não verificaram diferença na produção, composição e qualidade do leite, demonstrando o elevado potencial forrageiro dessa gramínea. No entanto, como sua qualidade é expressivamente

\footnotetext{
1 Trabalho financiado pela Fundação de Amparo à Pesquisa do Estado do Rio Grande do Sul (Fapergs).

2 Eng.-Agr., MSc., Laboratorista, Universidade de Passo Fundo, RS. E.mail: roberto@upf.br

${ }^{3}$ Eng.-Agr., Dra., Professor, Universidade de Passo Fundo. E.mail: simone@upf.br

${ }^{4}$ Eng.-Agr., PhD., Professor, Universidade de Passo Fundo. E.mail: durr@upf.br

5 Eng.-Agr., Cotrijuí, RS.

${ }^{6}$ Bióloga, aluna do curso de Mestrado em Zootecnia, UFRGS.

${ }^{7}$ Acadêmico do curso de Medicina Veterinária, Universidade de Passo Fundo, RS
} 
reduzida, ao longo da estação de crescimento, os produtores têm recorrido aos laboratórios para monitorar a qualidade da forragem disponível aos animais em pastejo. Gonçalves et al. (2001) não recomendam a realização de cortes de bermudas a partir dos 63 dias de crescimento para produção de feno, em virtude da expressiva redução na digestibilidade e consumo.

Os métodos tradicionais de avaliação do valor nutritivo de forrageiras envolvem processos químicofísicos e têm como principal limitação o longo tempo necessário para sua realização, em relação aos métodos eletrônicos. O uso desses métodos não é adotado rotineiramente pela maioria dos produtores, por se tratar de um conjunto de técnicas e análises sofisticadas, demoradas e de alto custo. O método de reflectância no infravermelho proximal (NIRS) é um método computadorizado, alternativo, rápido e de baixo custo para o produtor, que surgiu como alternativa aos métodos tradicionais. Em vez de utilizar reagentes químicos, esse método utiliza a luz infravermelha. A radiação infravermelha refletida é convertida em energia elétrica e transferida ao computador para interpretação, pois os componentes orgânicos das forragens absorvem e refletem a luz distintamente (Pioneer, 1995). No entanto, para que possa ser utilizado para as diferentes forragens, é imprescindível a calibração a partir de dados analíticos, pelo método de referência (químico).

A acurácia do método NIRS foi testada por Garcia-Ciudad et al. (1999), em gramíneas de pastagens semiáridas, incluindo bermudas, que indicaram sua validade para determinação do nitrogênio (N). Rodriguez \& Miller (2000) também observaram elevada correlação entre o $\mathrm{N}$ determinado pelo método de Kjeldahl e pelo NIRS, para bermudas, mas não verificaram precisão suficiente para a determinação de minerais.

Com a finalidade de oferecer aos produtores um serviço rápido e de baixo custo, utilizando o NIRS, efetuou-se este trabalho, com o objetivo de desenvolver curvas de calibração para quatro cultivares de bermuda.

\section{Materiais e Métodos}

No período de agosto de 1998 a fevereiro de 2001, foram coletadas e analisadas, no Centro de Pesquisa em Alimentação (CEPA) da Universidade de Passo Fundo, 129 amostras de forragem verde de Tifton 68, Tifton 85, Florakirk e Coastcross oriundas de diferentes regiões do Rio Grande do Sul. As amostras foram constituídas da parte aérea das plantas, contendo folhas, colmos e/ou inflorescências. No laboratório, as amostras foram secas a $60^{\circ} \mathrm{C}$, sob circulação de ar, por 48 horas, moídas (1 mm) em moinho do tipo Wiley, acondicionadas em vidros e analisadas pelo método NIRS, no qual os espectros foram armazenados. As análises foram realizadas em um espectrômetro Perstorp Analytical, Silver Spring, MD, modelo 5000, acoplado a um microcomputador equipado com software ISI versão 4.1 (Intrasoft International, University Park, PA). Paralelamente, foram realizadas análises pelo método químico para os seguintes parâmetros: matéria seca (MS), por meio de secagem a $105^{\circ} \mathrm{C}$ durante 24 horas, proteína bruta(PB), pelo método Kjeldhal(AOAC, 1995), fibra insolúvel em detergente neutro (FDN) e fibra insolúvel em detergenteácido(FDA), segundo Goering \& Van Soest (1970). Para minerais (Ca, P, K, Mg), as análises foram realizadas por meio de absorção atômica. Todas as determinações foram feitas em duplicatas.

Para o desenvolvimento de curvas de calibração, os resultados foram selecionados pelo programa Select e Center, com o objetivo de escolher as amostras representativas da população-alvo, com base na distância Mahalanobis ("H” de 0,6) entre a amostra e seu grupo e deste com sua vizinhança (Shenk \& Wetterhaus, 1991). Para a geração das equações, foi utilizado o tratamento matemático do programa Match (Shenk \& Wetterhaus, 1993). Posteriormente, fez-se a análise de regressão, tendo como variável independente os resultados das análises químicas e, como variável dependente, os resultados do NIRS. A avaliação do grau de ajuste foi feita por intermédio dos coeficientes de determinação $\left(\mathrm{R}^{2}\right)$. Para verificar diferenças estatísticas entre as cultivares quanto aos diferentes componentes das forragens, foi realizada a análise de variância, utilizando-se o Proc GLM do pacote estatístico SAS (1995), sendo as médias comparadas pelo teste $\mathrm{t}$.

\section{Resultados e Discussão}

O número de amostras analisadas, a amplitude e as médias obtidas para os parâmetros de valor nutritivo pelo método NIRS são apresentados na Tabela 1. Os valores médios de FDN $(69,04 \%)$ e de FDA $(34,32 \%)$ foram inferiores aos obtidos por Rocha et al. (2001); para FDN, de 73 a $75 \%$ e, para FDA, de 39 a 40\%, respectivamente. A média de PB foi elevada (16,75\%), corroborando os dados de Monson \& Burton (1982),

R. Bras. Zootec., v.33, n.4, p.838-842, 2004 
embora a elevada amplitude (9,09 a 25,2\%) tenha indicado que as amostras analisadas foram representativas de forragens de distintos graus de maturação.

Para os minerais, os níveis obtidos estão de acordo com os encontrados em gramíneas forrageiras (Spears, 1994), embora as concentrações sejam dependentes de fatores edáficos e de manejo. No Brasil, Palhano \& Haddad (1992) verificaram níveis máximos de $0,26 \%$ para Ca; $0,28 \%$ para $\mathrm{P} ; 1,7 \%$ para K e 0,40\% para Mg na cv. Coastcross colhida até 70 dias após a emergência.

Os resultados da calibração para as diferentes variáveis encontram-se na Tabela 2 . Os coeficientes de determinação foram similares aos encontrados por Shenk \& Westerhaus (1993), Pires \& Prates (1998), Fontaneli et al. (1998) e Fontaneli et al. (2002), com outras forragens.

Os erros-padrão de validação cruzada (EPVC), quando comparados com os trabalhos de Robert \& Demarquilly (1986), Barton \& Windhan (1988) e Marten et al. (1983), podem ser considerados baixos para PB (0,46\%), FDN $(0,64 \%)$ e FDA $(0,40 \%)$, em função da melhor acurácia da técnica de referência (Shenk \& Westerhaus, 1991), uma vez que esses pesquisadores obtiveram valores de EPVC de 0,68\% para $\mathrm{PB}, 1,79 \%$ para FDN e $0,98 \%$ para FDA. O EPVC também foi baixo para MS (0,23\%), o que foi atribuído à imediata determinação após leitura do espectro. Alomar et al. (1998) afirmam que os valores dos EPVC são indicadores de qualidade para as equações desenvolvidas e, para que as equações sejam consideradas aceitáveis, devem ser inferiores a um terço do valor dos desvios-padrão dos métodos de referência (Tabela 1). Portanto, observa-se, no presente trabalho, que esse índice não foi alcançado somente pelas equações de Ca e Mg, o que está de acordo com a literatura para tais componentes.

As concentrações de PB e FDN foram significativamente diferentes entre as cultivares $(\mathrm{P}<0,10)$, ao passo que não diferiram para FDA (Figura 1). Tais resultados são similares aos obtidos por Monson \& Burton (1982) na cv. Tifton 68.

Com a cv. Coastcross 1, Palhano \& Haddad (1992) verificaram teores mais elevados de fibra (máximo de $46 \%$ de FDA e cerca de $80 \%$ de FDN) aos 70 dias de crescimento. Rocha et al. (2001) obtiveram teores de FDN de 72,14; 73,03 e 75,16\% para as cvs. Coastcross, Tifton 68 e Tifton 85, respectivamente.

Com relação aos minerais, os coeficientes de determinação podem ser considerados muito bons, em comparação com os obtidos por Rodriguez \& Miller (2000), que foram inferiores a 0,50 e que, inclusive para $\mathrm{P}$, não obtiveram correlação entre o NIRS e o método químico. Tal fração não sofre alteração pela ação da luz infravermelha e, portanto, não existem bandas de absorção para os minerais puros. Segundo Clark et al. (1987), são necessários mais estudos para determinar a relação entre a composição, relativamente elevada, de ácidos orgânicos e a concentração individual de minerais

Tabela 1 - Composição química de Cynodon spp. determinada pelos métodos NIRS e químico Table 1 - Chemical composition of Cynodon spp. determined by NIRS and chemical methods

\begin{tabular}{|c|c|c|c|c|c|c|c|}
\hline \multirow[t]{2}{*}{$\begin{array}{l}\text { Parâmetro } \\
\text { Parameter } \\
(\%)\end{array}$} & \multirow[t]{2}{*}{$\begin{array}{c}\mathrm{N}^{\mathrm{o}} \text { de amostras } \\
N \text {. of samples }\end{array}$} & \multicolumn{2}{|c|}{$\begin{array}{l}\text { Amplitude } \\
\text { Range } \\
\text { (\%) }\end{array}$} & \multicolumn{2}{|c|}{$\begin{array}{l}\text { Média } \\
\text { Mean } \\
(\%)\end{array}$} & \multicolumn{2}{|c|}{$\begin{array}{c}\text { Desvio-padrão } \\
\text { Standard } \\
\text { deviation }(\%)\end{array}$} \\
\hline & & NIRS & $\begin{array}{l}\text { Químico } \\
\text { Chemical }\end{array}$ & NIRS & $\begin{array}{l}\text { Químico } \\
\text { Chemical }\end{array}$ & NIRS & $\begin{array}{l}\text { Químico } \\
\text { Chemical }\end{array}$ \\
\hline $\begin{array}{l}\mathrm{PB} \\
\mathrm{CP}\end{array}$ & 121 & $9,09-25,20$ & $8,46-24,53$ & 16,75 & 16,61 & 2,91 & 3,07 \\
\hline $\begin{array}{l}\text { FDN } \\
N D F\end{array}$ & 128 & $60,15-78,04$ & $59,75-78,30$ & 69,04 & 69,64 & 3,45 & 3,42 \\
\hline $\begin{array}{l}\text { FDA } \\
A D F\end{array}$ & 120 & $25,32-47,01$ & $25,15-47,16$ & 34,32 & 34,29 & 3,69 & 3,78 \\
\hline $\begin{array}{l}\text { MS } \\
D M\end{array}$ & 121 & $90,05-98,25$ & $89,92-98,16$ & 94,15 & 94,24 & 2,02 & 2,00 \\
\hline $\mathrm{Ca}$ & 127 & $0,33-0,70$ & $0,21-0,69$ & 0,48 & 0,47 & 0,08 & 0,08 \\
\hline $\mathrm{P}$ & 125 & $0,17-0,47$ & $0,18-0,47$ & 0,34 & 0,34 & 0,07 & 0,07 \\
\hline $\mathrm{K}$ & 124 & $1,43-3,89$ & $1,44-3,89$ & 2,63 & 2,61 & 0,53 & 0,54 \\
\hline $\mathrm{Mg}$ & 125 & $0,20-0,29$ & $0,20-0,28$ & 0,25 & 0,25 & 0,02 & 0,02 \\
\hline
\end{tabular}

\section{R. Bras. Zootec., v.33, n.4, p.838-842, 2004}


em forragens. Os minerais podem estar tanto complexados organicamente (ou na forma de quelatos), quanto na forma de sais e íons. Assim, os primeiros poderiam ser determinados, ao contrário das formas iônica e salina, que não absorvem energia na região do infravermelho proximal.
Os teores de minerais verificados em cada uma das cultivares são apresentados na Figura 2. Palhano \& Haddad (1992) relataram valores máximos de, aproximadamente, 0,26\% (Ca); 1,75\% (K); 0,20\% (P) e $0,38 \%(\mathrm{Mg})$ para a cv. Coastcross 1 , inferiores aos obtidos no presente trabalho, com exceção do

Tabela 2 - Variáveis da equação de validação para determinação de PB, FDN, FDA, MS, Ca, P, K e Mg Table 2 - Variables of the validation equation for determination of $C P, N D F, A D F, D M, C a, P, K$ e Mg

\begin{tabular}{|c|c|c|c|c|c|c|}
\hline $\begin{array}{l}\text { Parâmetro } \\
\text { Parameter }\end{array}$ & $\begin{array}{c}\text { Desvio- } \\
\text { padrão } \\
\text { Standar } \\
\text { ddeviation } \\
(\%) \\
\end{array}$ & $\begin{array}{l}\mathrm{R}^{2} \\
R^{2}\end{array}$ & $\begin{array}{c}\text { Erro-padrão } \\
\text { de calibração } \\
\text { Calibration } \\
\text { standard error } \\
(\%) \\
\end{array}$ & $\begin{array}{c}\text { Erro-padrão } \\
\text { validação cruzada } \\
\text { Crossed validation } \\
\text { standard error } \\
(\%) \\
\end{array}$ & $\begin{array}{c}\mathrm{R}^{2} \\
\text { validação } \\
R^{2} \\
\text { validation }\end{array}$ & $\begin{array}{c}\text { Tratamento } \\
\text { matemático } \\
\text { Mathematic } \\
\text { treatment }\end{array}$ \\
\hline $\begin{array}{l}\mathrm{PB} \\
C P\end{array}$ & 2,91 & 0,98 & 0,38 & 0,46 & 0,98 & $1,4,4,1$ \\
\hline $\begin{array}{l}\text { FDN } \\
N D F\end{array}$ & 3,45 & 0,97 & 0,60 & 0,64 & 0,97 & $1,4,4,1$ \\
\hline $\begin{array}{l}\text { FDA } \\
A D F\end{array}$ & 3,69 & 0,99 & 0,35 & 0,40 & 0,99 & $1,4,4,1$ \\
\hline $\begin{array}{l}\text { MS } \\
D M\end{array}$ & 2,02 & 1,00 & 0,14 & 0,23 & 0,99 & $1,4,4,1$ \\
\hline $\mathrm{Ca}$ & 0,08 & 0,92 & 0,02 & 0,03 & 0,81 & $1,4,4,1$ \\
\hline $\begin{array}{l}\mathrm{P} \\
\mathrm{K}\end{array}$ & $\begin{array}{l}0,07 \\
053\end{array}$ & $\begin{array}{l}0,97 \\
099\end{array}$ & $\begin{array}{l}0,01 \\
005\end{array}$ & $\begin{array}{l}0,02 \\
0,99\end{array}$ & $\begin{array}{l}0,94 \\
0,97\end{array}$ & $\begin{array}{l}1,4,4,1 \\
144\end{array}$ \\
\hline $\mathrm{Mg}$ & $\begin{array}{l}0,33 \\
0,02\end{array}$ & $\begin{array}{l}0,99 \\
0,72\end{array}$ & $\begin{array}{l}0,05 \\
0,01\end{array}$ & $\begin{array}{l}0,09 \\
0,01\end{array}$ & $\begin{array}{l}0,9 / \\
0,69\end{array}$ & $\begin{array}{l}1,4,4,1 \\
1,4,4,1\end{array}$ \\
\hline
\end{tabular}

$\mathrm{PB}=$ proteína bruta, $\mathrm{FDN}=$ fibra insolúvel em detergente neutro, FDA= fibra insolúvel em detergente ácido, MS= matéria seca, $\mathrm{Ca}=$ cálcio, $\mathrm{P}=$ fósforo, $\mathrm{K}=$ potássio, $\mathrm{Mg}=$ magnésio.

$C P=$ crude protein, $N D F=$ neutral detergent fiber, $A D F=$ acid detergent fiber, $D M=$ dry matter, $C a=$ calcium, $P=$ phosphorus,$K=$ potash, $M g=$ magnesium.

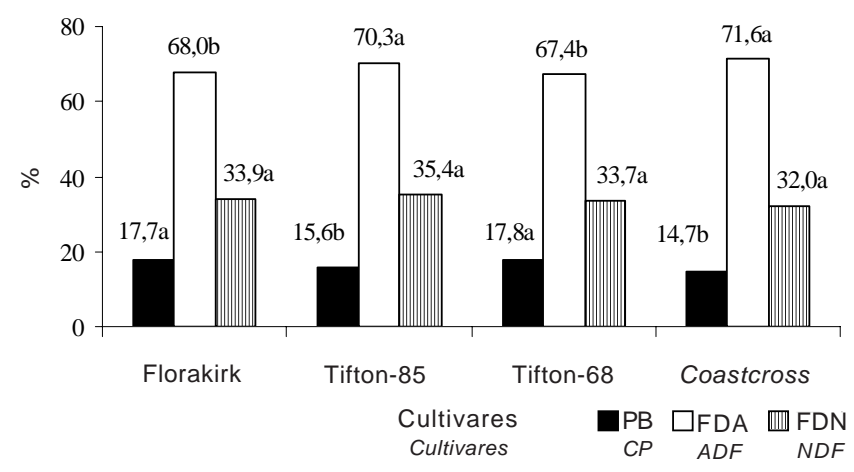

Figura 1 - Concentrações de proteína bruta (PB), fibra insolúvel em detergente neutro (FDN) e fibra insolúvel em detergente ácido (FDA) de cultivares de Cynodon spp., determinados pelo método NIRS. Médias seguidas pela mesma letra não diferem estatisticamente pelo teste $t(P>0,10)$.

Figure 1 - Crude protein (CP), neutral detergent fiber (NDF) and acid detergent fiber (ADF) concentration of Cynodon sp. cultivars determined by NIRS. Means followed by the same letter do not differ by $t$ test $(P<.10)$.

R. Bras. Zootec., v.33, n.4, p.838-842, 2004

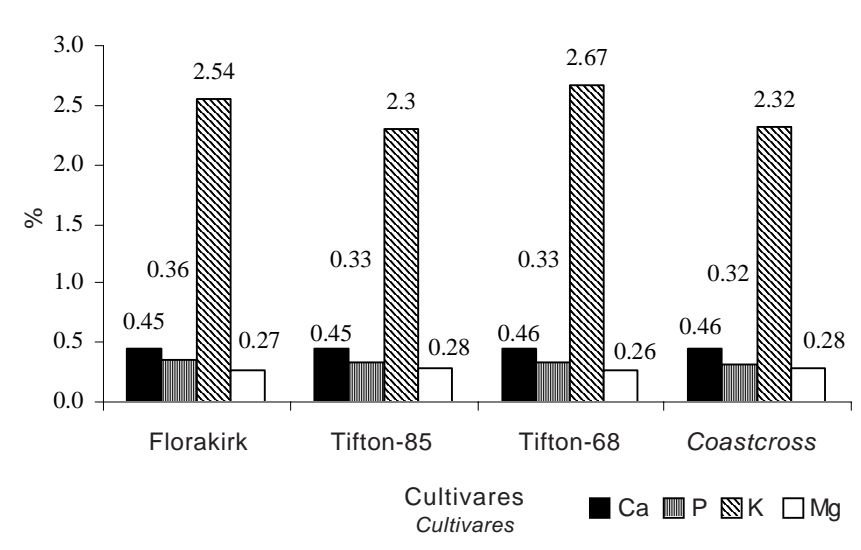

Figura 2 - Concentrações de minerais em cultivares de Cynodon spp. determinados pelo método NIRS (teores médios nos cultivares estudados não diferiram estatisticamente entre si pelo teste $\mathrm{t}$ ).

Figure 2 - Mineral concentrations in Cynodon spp. cultivars determined by NIRS (mean content values from studied cultivars did not differ statistically by $t$ test). 
Mg. No entanto, sabe-se que a concentração de minerais é dependente dos níveis de adubação, da idade das plantas e da relação folha:caule, bem como do efeito da diluição na massa seca sobre o teor dos elementos (Gomide, 1976). No estudo de Palhano \& Haddad (1992), foi verificada, com o tempo, redução de Ca, Mg e K.

Apesar de a literatura não apresentar bons resultados para predição de minerais pelo NIRS, este trabalho obteve índices satisfatórios na calibração dos mesmos, que podem estar relacionados a adequadas associações entre bandas espectrais e à fração mineral complexada à matriz orgânica ou, ainda, à alta correlação entre o teor de minerais e a flutuações de outros compostos orgânicos presentes nas amostras.

\section{Conclusões}

O método de espectrometria de reflectância no infravermelho proximal (NIRS) apresentou elevada acurácia para determinar teores de PB, FDA e FDN em cultivares de Cynodon spp., mostrando índices de calibração satisfatórios para determinação de minerais.

\section{Literatura Citada}

ALOMAR, D.; FUCHSLOCHER, R. Fundamentos de la espectroscopia de reflectancia en el infrarojo cercano (NIRS) como metodo de analisis de forrajes. Agro Sur, v.26, n.1, p.88-104, 1998.

ASSOCIATION OF ANALYTICAL CHEMIST - AOAC. Official methods of analysis. Washington: 1995. 2038p.

BARTON, H.F.E.; WINDHAN, W. Determination of aciddetergent fiber and crude protein in forages by near infrared reflectance spectroscopy (NIRS): collaborative study. Journal Association Official Analytics Chemistry, v.71, p. 1162-1167, 1988.

CLARK, D.H.; MARYLAND, H.F.; LAMB, R.C. Mineral analysis of forages with near infrared reflectance spectroscopy. Agronomy Journal, v.79, p.485-490, 1987.

FONTANELI, R.S.; SCHULZ, J.G.; DÜRR, J.W. Avaliação da qualidade forrageira por espectrometria do infravermelho proximal. In: REUNIÃO ANUAL DA SOCIEDADE BRASILEIRA DE ZOOTECNIA, 35., 1998, Botucatu. Anais... Viçosa, MG: Sociedade Brasileira de Zootecnia, 1998. p.286-287.

FONTANELI, R.S.; DÜRR, J. W.; BASSO, S.M. et al. Avaliação da qualidade de silagens de milho através da espectrometria de refletância no infravermelho proximal. Revista Brasileira de Zootecnia, v.31, n.2, p.594-598, 2002.

GARCIA-CIUDAD, A.; RUANO, A.; BECERRO, F. et al. Assessment of the potential of NIR spectroscopy for the estimation of nitrogen content in grasses from semiarid grasslands. Animal Feed Science and Technology, v.77, p.1-2, 1999.

GOERING, H.K., Van SOEST, P.J. Forage fiber analysis: apparatus reagents, procedures and some applications. USDA: Washington, 1970. (Agric. Handbook, 379).

GOMIDE, J.A. Composição mineral de gramíneas e leguminosas forrageiras tropicais. In: SIMPÓSIO LATINOAMERICANO SOBRE PESQUISA EM NUTRIÇÃO MINERAL, 1976, Belo Horizonte. Anais... Belo Horizonte: Universidade Federal de Minas Gerais, 1976. p.20-33.

GONÇALVES, G.D.; SANTOS, G.T.; DAMASCENO, J.C. et al. Determinação do consumo e da digestibilidade de fenos de Tifton 85 em diferentes idades de corte. In: REUNIÃO ANUAL DA SOCIEDADE BRASILEIRA DE ZOOTECNIA, 39., 2001, Piracicaba. Anais... Viçosa, MG: Sociedade Brasileira de Zootecnia, 2001. p.63-64.

JOBIM, C.C.; FERREIRA, G.A.; SANTOS, G.T. et al. Produção e composição do leite de vacas da raça holandesa alimentadas com fenos de alfafa e de Tifton-85 e silagem de milho. In: REUNIÃO ANUAL DA SOCIEDADE BRASILEIRA DE ZOOTECNIA, 39., 2001, Piracicaba. Anais... Viçosa, MG: Sociedade Brasileira de Zootecnia, 2001. p.106-107.

MARTEN, G.C.; HALGERSON, J.L.; CHERNEY, J.H. Quality prediction of small grain forages by near infrared reflectance spectroscopy. Crop Science, v.23, p.94-96, 1983.

MONSON, W.G.; BURTON, G.W. Harvest frequency and fertilizer effects on yield, quality and persistence of height bermudagrass. Agronomy Journal, v.74, p.371-374, 1982.

PALHANO, A.L.; HADDAD, C.M. Exigências nutricionais e valor nutritivo de Cynodon dactylon (L.) Pers. cv. CoastCross $\mathrm{n}^{\circ} 1$. Pesquisa Agropecuária Brasileira, v.27, p.1429-1438, 1992.

PIONEER. Pioneer forage manual - a nutritional guide. Iowa: Pioneer Hi-Bred International, 1995. 54p.

PIRES, F.F.; PRATES, E.R. Uso da técnica da espectrometria de reflectância no infravermelho próximo (NIRS) na predição da composição química da alfafa (Medicago sativa L.). Revista Brasileira de Zootecnia, v.27, p.1076-1081, 1998.

ROBERT, P.D.; DEMARQUILLY, C. Use of near infrared reflectance spectroscopy as a tool for screening treated forages and by-products. Animal Feed Science and Technology, v.16, p.215-224, 1986.

ROCHA, G.P.; EVANGELISTA, A.R.; PAIVA, P.C.A. et al. Digestibilidade e fração fibrosa de três gramíneas do gênero Cynodon. Ciência Agrotécnica, v.25, p.396-407, 2001.

RODRIGUEZ, I.R.; MILLER, G.L. Using near infrared reflectance spectroscopy to schedule nitrogen. Agronomy Journal, v.92, p.423-427, 2000.

STATISTICAL ANALYSES SYSTEM - SAS. User'g guide. Cary: 1995

SHENK, J.; WESTERHAUS, M. New standardization and calibration procedure for NIRS analytical systems. Crop Science, v.31, p.1694-1692, 1991.

SHENK, J.; WESTERHAUS, M. Analysis of agriculture and food products by near infrared reflectance spectroscopy. Port Matilda: Penn State University and Infrasoft International, 1993. 116p

SPEARS, J.W. Minerals in forages. In: FAHEY, G.C. (Ed.). Forage quality, evaluation and utilization. Madison: ASA, 1994. p.281-317.

Recebido em: 11/12/02

Aceito em: 04/11/03 